\title{
Effect of an office ergonomic randomised controlled trial among workers with neck and upper extremity pain
}

\author{
Jonathan Dropkin, ${ }^{1}$ Hyun Kim, ${ }^{1}$ Laura Punnett, ${ }^{2}$ David H Wegman, ${ }^{2}$ Nicholas Warren, ${ }^{3}$ \\ Bryan Buchholz ${ }^{2}$
}

${ }^{1}$ Department of Population Health, North Shore-LIJ Health System, Hofstra North Shore-LIJ School of Medicine, Great Neck, New York, USA ${ }^{2}$ Department of Work Environment, University of Massachusetts Lowell, Lowell, Massachusetts, USA

${ }^{3}$ Ergonomic Technology Center, University of Connecticut Health Center, Farmington, Connecticut, USA

\section{Correspondence to}

Dr Jonathan Dropkin, Department of Population Health, North Shore-LIJ Health System, Hofstra North Shore-LIJ School of Medicine, 175 Community Drive, Great Neck, NY 11021, USA; jdropkin@nshs.edu

Received 10 February 2014 Revised 13 August 2014 Accepted 26 August 2014 Published Online First 16 September 2014

\section{ABSTRACT}

Background Office computer workers are at increased risk for neck/upper extremity (UE) musculoskeletal pain. Methods A seven-month office ergonomic intervention study evaluated the effect of two engineering controls plus training on neck/UE pain and mechanical exposures in 113 computer workers, including a 3-month follow-up period. Participants were randomised into an intervention group, who received a keyboard/mouse tray (KBT), touch pad (TP) for the non-dominant hand and keyboard shortcuts, and a control group who received keyboard shortcuts. Participants continued to have available a mouse at the dominant hand. Outcomes were pain severity, computer rapid upper limb assessment (RULA), and hand activity level. Prevalence ratios (PRs) evaluated intervention effects using dichotomised pain and exposure scores.

Results In the intervention group, the dominnt proximal UE pain $\mathrm{PR}=0.9,95 \% \mathrm{Cl} 0.7$ to 1.2 and the dominant distal UE PR $=0.8,95 \% \mathrm{Cl} 0.5$ to 1.3 , postintervention. The non-dominant proximal UE pain $\mathrm{PR}=1.0,95 \% \mathrm{Cl} 0.8$ to 1.4 , while the non-dominant distal UE $P R=1.2,95 \% \mathrm{Cl} 0.6$ to 2.2 , postintervention. Decreases in non-neutral postures were found in two RULA elements (non-dominant UE PR $=0.9,95 \% \mathrm{Cl} 0.8$ to 0.9 and full non-dominant RULA PR=0.8, 95\% $\mathrm{Cl} 0.8$ to 0.9 ) of the intervention group. Hand activity increased on the non-dominant side ( $P R=1.4,95 \%$ Cl 1.2 to 1.6) in this group.

Conclusions While the intervention reduced nonneutral postures in the non-dominant UE, it increased hand activity in the distal region of this extremity. To achieve lower hand activity, a KBT and TP used in the non-dominant hand may not be the best devices to use.

\section{BACKGROUND}

The magnitude of computer-related neck and upper extremity (UE) musculoskeletal pain is considerable; its prevalence can be as high as $62 \%{ }^{1}$ The related financial burden to society is substantial. The US Bureau of Labor Statistics recently reported that illnesses associated with repetitive motion involving 'micro-tasks' resulted in three times as many lost workdays as all other types of work-related illnesses. ${ }^{2}$

Most office ergonomic intervention studies have examined primary prevention. In a review of primary prevention of musculoskeletal outcomes (MSOs) and ergonomic measures, interventions

\section{What this paper adds}

- Most office ergonomic intervention studies have examined primary prevention, with little attention focused on secondary prevention.

- There appear to be no secondary prevention studies that have examined health and exposure outcomes when simultaneously using pointing devices in both hands.

- In this randomised controlled trial, no significant differences in pain between groups were found in any anatomical regions, postintervention; trends in improvements in non-neutral postures in all regions, along with higher hand activity on the non-dominant side were seen in the intervention group, postintervention.

- Other types of pointing devices in right and left hands, coupled with forearm supports on a low, negatively pitched platform, may still have a role in secondary prevention.

- To achieve lower pain in the non-dominant upper extremity, a keyboard/mouse tray and touch pad in the non-dominant hand may not be the best devices to use.

included ergonomic training, forearm supports and alternative pointing devices. ${ }^{3}$ The review found moderate evidence that ergonomic training was ineffective, while the use of forearm supports reduced incident neck and shoulder MSOs. Using an alternative mouse on the dominant side did not lead to beneficial effects. ${ }^{3}$

Most secondary prevention studies have examined health outcomes, with little attention focused on intermediate exposure outcomes. ${ }^{4}$ Two reviews of secondary prevention in office ergonomics noted that work practice controls alone had little effect on pain reduction, and more studies were needed on pointing devices. ${ }^{4} 5$ One randomised intervention study that examined trackball use found a decrease in right UE pain, where $98 \%$ of participants used the track ball in the right hand. ${ }^{6}$ To date, no secondary prevention studies have examined the effect of a touch pad (TP) on pain and mechanical exposure outcomes in computer workers. 
While return-to-work programmes following a work-related disability involving the musculoskeletal system have contributed to our understanding of secondary prevention, ${ }^{78}$ limited information exists on worker presenteeism with musculoskeletal pain. ${ }^{9}$ There also appear to be no secondary prevention studies that examined health and exposure outcomes when simultaneously using pointing devices in both hands.

The use of two devices in symptomatic computer workers may assist with recovery. Based on an exposure-response model, ${ }^{10}$ an exacerbation of pain would likely occur sooner and more frequently in the dominant UE of symptomatic workers (the extremity using the principal pointing device). One study found $17 \%$ of symptomatic computer workers changed mouse use from the dominant to the non-dominant UE (the extremity initially not using a pointing device) over the workday or alternated between mousing hands to manage symptoms in the dominant UE. ${ }^{11}$

The objective of this study was to examine the effect of an adjustable keyboard/mouse tray (KBT) and TP for the nondominant hand plus training on their use to symptomatic computer workers with substantial occupational computer use. The outcomes studied were non-specific neck/UE musculoskeletal pain and mechanical exposure. We hypothesised the intervention group would have a reduction in severity and prevalence of pain and less mechanical exposure to the dominant UE because certain pointing activities would be shifted to the other hand. While a small increase in mechanical exposure in the nondominant UE was expected, we hypothesised this would not measurably exacerbate pain on this side.

\section{METHODS}

\section{Trial design}

This was a randomised controlled trial with baseline and follow-up (postintervention) assessments 7 months apart with an intervention and a control group. The intervention group received a KBT, a TP in the non-dominant UE (figure $1 \mathrm{~A}$ ), and training on these devices. The control group did not receive any engineering controls. All participants continued to have available a traditional mouse located at the dominant hand (figure $1 \mathrm{~A}, \mathrm{~B})$. Both intervention and control groups also received training on keyboard shortcuts (minor intervention) after the intervention group received their (major) intervention. Internal Review Boards at our institutions approved the study protocol and consent forms.

\section{Setting and location}

The study group was a legislative branch of state government with 20 departments, located in the northeastern USA.
Employees within these departments worked as support staff for state legislators or in non-partisan departments (eg, information technology). Legislators were ineligible to participate per a request from management.

\section{Eligibility criteria}

Participants had to be permanent, year-round employees but did not have to be full-time employees. Year-round employees work all year, during the legislative session and interim period when legislators are not in session. 'Sessional' employees only work during the legislative session. Additional inclusion criteria were: work at least $4 \mathrm{~h} /$ day on a desktop computer, non-specific neck/ UE musculoskeletal pain (1 or greater on the pain scale described below) at the time of screening, and no history of acute traumatic injury to the neck/UE in the past year.

\section{Intervention}

Engineering controls were installed at night. Members of the intervention group were given an adjustable 27-inch wide KBT (K/V Waterloo, Kitchener, Ontario, Canada and Grand Stands, Monrovia, California, USA) and a Smart Cat TP (Cirque Corporation, Salt Lake City, Utah, USA), positioned adjacent to the keyboard. The TP was positioned on the side of the nondominant UE. The angle of the KBT was set in a $10^{\circ}$ negative tilt. ${ }^{12}$ A padded wrist rest was integrated into the tray. The TP was tented approximately $30^{\circ}$ above the horizontal. ${ }^{13}$

Training on these devices was conducted on agency time and lasted $1 \mathrm{~h}$. The rationale for engineering controls and method of use was explained to each participant. Participants were encouraged to use 11 programmable features on the TP. They also received a diagram of the $\mathrm{TP}$ and directions on the features. Demonstration and supervised practice followed. Each participant repeated the demonstrated actions until she/he appeared to understand how to use both devices.

Another 45 min training session was conducted 1 month later for the intervention group to review the engineering controls. Participants from intervention and control groups were then given an additional 45 min of training on keyboard shortcuts along with written instructions on each shortcut. Training for groups was one-on-one.

\section{Health outcome}

At baseline and postintervention, the same intervieweradministered survey was used to assess pain severity. A modified five-point verbal rating scale was used ${ }^{14} 15$ to cover 12 upper body anatomical regions: neck and right/left upper back, right/ left shoulder, right/left elbow, right/left forearm, right/left wrist
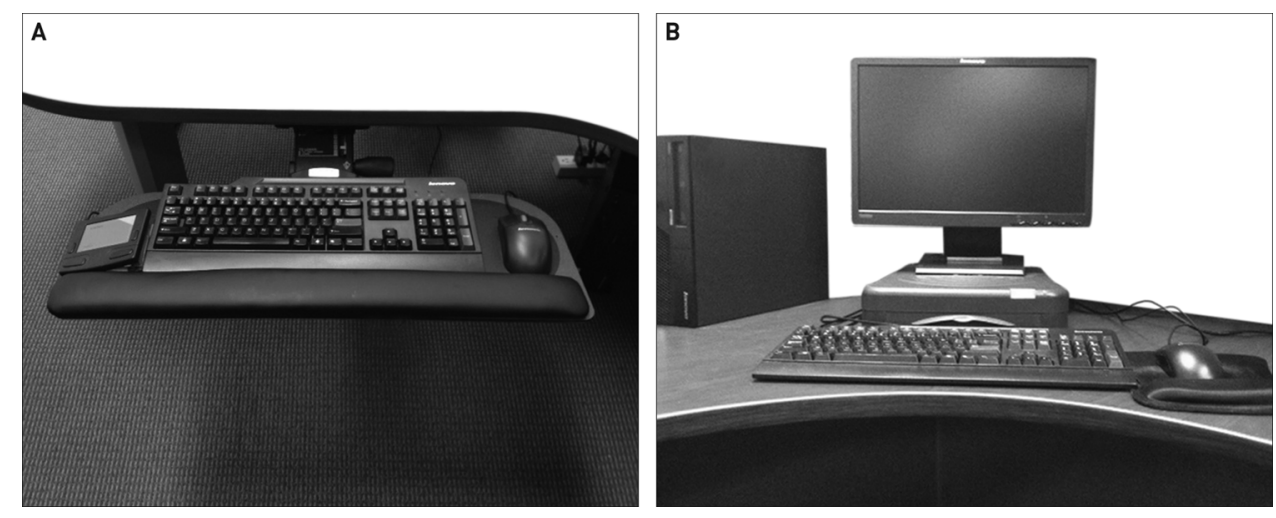

Figure 1 ( $A$ and $B$ ) Example of a workstation with the intervention and example of a workstation without the intervention. 
and right/left fingers. One question was asked for each anatomical region of interest, such as 'In the past 4 weeks, how much pain, on average, did you have in your dominant neck/upper back?' Response anchors were: (0) no pain; (1) mild pain (pain present but does not limit activity); (2) nagging, uncomfortable pain (can do most activities with rest); (3) miserable, distressing pain (unable to do some activities); and (4) intense, dreadful pain (unable to do most activities).

For analyses, pain scores were combined into two UE regions (proximal and distal) on each side. The right and left proximal regions were comprised of two parts, the neck/upper back and shoulder. The right and left distal regions consisted of the elbow, forearm, wrist and fingers. Mean pain scores for each region were calculated by summing the scores for all joints of each region and dividing by the number of joints.

\section{Secondary outcomes}

Other possible outcomes from the intervention were also examined. These comprised: change in primary mousing hand, use of UE support, sick leave or medical care for a musculoskeletal condition, exacerbation of pain, a modified work ability index (WAI), ${ }^{16}$ trouble sleeping, hours of keyboard and pointing device use, static posture, finger effort, psychosocial exposures and ergonomic knowledge.

\section{Exposure outcomes}

Identical observational exposure assessments were performed at baseline and postintervention. A modified computer rapid upper limb assessment (RULA) ${ }^{17} 18$ and the hand activity level $(\mathrm{HAL})^{19}$ were used to examine body posture and hand activity on both sides.

Computer RULA was designed to provide a posture-coding framework to score neutral/non-neutral postures throughout the body, but was modified to score only non-neutral postures. The score of all RULA elements, consisting of the dominant or nondominant UE, the neck and trunk ('spine'), and lower extremities could range from 1 to 83 . The sum of the spine and lower extremities could range from 0 to 50 . The dominant or nondominant UE score could range from 1 to 33 .

HAL comprises a 10 -point scale with five verbal anchors. HAL integrates the observer's assessment of wrist and finger motion speed with duration and frequency of observed pauses. HAL could range from 0 to 10 . Higher values for both exposure measures represent greater mechanical exposure.

Random selection in one of the 20 departments after the start of the workday initiated the work-sampling window. The first participant encountered in the department was observed for $33 \mathrm{~s}$ consecutive time frames $(15 \mathrm{~min})$. Each time frame was coded in this sequence: (1) Computer RULA neck/right upper back, right UE, forward head; (2) Computer RULA neck/left upper back, left UE, trunk/lower extremities; (3) right HAL; (4) left HAL and (5) task (five tasks were defined, consisting of data entry, data acquisition, word processing, interactive communication/email, programming/graphics). The worker closest to the initial worker was then observed, and so on, up to a maximum of eight workers. This entire sequence was repeated once after lunch on the same eight workers. In total, $30 \mathrm{~min}$ of observational data on 1 day were obtained per worker at baseline and postintervention.

\section{Survey questionnaires}

At baseline, a structured questionnaire was intervieweradministered or self-administered to all participants. The items covered five domains: (1) individual factors (interviewer- administered), (2) department and job categories (self-report), (3) temporal and other mechanical exposures (intervieweradministered), (4) psychosocial exposures (self-report) and (5) ergonomic knowledge (self-report).

Individual factors included demographics, general and musculoskeletal health history, and one slightly modified question from the WAI. Department job categories consisted of caucuses, technical branches and management. Job titles consisted of assistants, directors, analysts and other. Mechanical and temporal exposures included hours of computer use, other repetitive work, years working at the agency and other computer work outside of the agency. Psychosocial factors consisted of one composite measure of job strain from an alternative formulation of the Job Content Questionnaire (JCQ), and one multimeasure (four items) composite score for supervisor support based on the JCQ. ${ }^{20} 21$ The composite job strain measure was comprised of five items for psychological job demands and nine items for decision latitude. It was defined as $\mathrm{y}=(0.5)$ psychological job demands-(0.5) decision latitude (use of skills plus decisionmaking latitude), giving a continuous linear function term. Job satisfaction was also collected. ${ }^{22}$ Ergonomic knowledge comprised four items: overall knowledge and knowledge of risk factors, correct posture and correct workspace. ${ }^{23}$ One question was asked for each item of interest. For example, for 'knowledge of correct workspace,' participants were asked 'Do you have knowledge of what is an ergonomically correct computer workspace?' A four-point verbal rating scale was used, consisting of none, fair, moderate and a lot.

Variables that could change over time were reassessed postintervention with identical instruments. These included demographics, general and musculoskeletal health history, physical activity and mechanical exposures.

\section{Sample size}

With approximately 57 participants per group, we would have $80 \%$ power to detect a $23 \%$ difference in musculoskeletal pain severity between intervention and control groups if the baseline median pain score was $2,{ }^{24}$ where $\leq 2=$ no pain/mild pain and $\geq 2=$ uncomfortable to severe pain (scale range $=0-4$ ) and if the baseline pain prevalence was $62 \%{ }^{1}$

\section{Potential sources of bias}

Performance bias was addressed by examining baseline and postintervention determinants between groups, although blinding was impossible postintervention. As blinding was impossible, detection bias may have occurred. Attrition bias was addressed by determining the reasons for loss to follow-up. The engineering controls used for the intervention may have reduced contamination bias, since the control group would most likely need the identical engineering controls to achieve similar outcomes. Selection bias based on differences in baseline determinants and baseline outcomes between groups was addressed by randomisation. Selection bias was likely reduced by our allocation concealment during randomisation, which is described below.

\section{Recruitment and randomisation}

Within a 3-month period, management sent two emails and a newsletter to all eligible agency employees, briefly stating the purpose of the project. The emails did not describe inclusion criteria. The research ergonomist then e-mailed all eligible employees explaining the purpose of the study in detail and asking them to reply with their work telephone numbers if they were interested in participating. Once contacted, telephone 
consent was obtained followed by a 15 min screening interview to determine if eligibility criteria were met.

Random allocation was conducted by an epidemiologist blind to study objectives to avoid predictable sequences. The epidemiologist recorded the allocation at the same time he preformed the randomisation procedure to avoid manipulation of assignment. A simple individual randomisation scheme was used. Stata V.11 (StataCorp, College Station, Texas, USA) was used to generate a dichotomous $(0,1)$ randomisation sequence analogous to a repeated fair coin tossing for each participant. Thus, participants could be randomly assigned to either the intervention or control group based on a predefined 50\% event probability, where $0=$ control group and $1=$ intervention group. To prevent unbalanced group randomisation, the randomisation syntax was reiterated until intervention and control groups each had approximately 57 participants.

Allocation concealment and implementation of assignments followed the sequence generation and were kept secret from researchers and participants until the latter group was consented and enrolled, after baseline evaluations were performed and after all participants were assigned to their groups by the epidemiologist. Each participant was then given an identical sealed envelope by the ergonomist, which contained the allocation assignment for that participant.

\section{Statistical analysis}

Only participants who had both baseline and postintervention measures were included in analyses. To compare exposures, time-weighted averages for RULA and HAL scores were calculated for each day by averaging non-neutral posture and hand activity scores over the two $15 \mathrm{~min}$ observation periods, multiplying by the percent of each task performed over the periods, and then summing these task means. Graphical univariate distributions of continuous variables were used to identify outliers and determine whether data were normally distributed. Selected continuous and ordinal variables were converted to categorical variables. Bivariate scatter-plots were visually examined to determine whether relations were linear or non-linear. Baseline distributions were compared between groups with $\mathrm{t}$ test or $\chi^{2}$ test. Means of outcome variables were compared in the intervention and control group using paired t tests (ie, pretest vs post-test mean comparisons by group). Findings were considered statistically significant at $\mathrm{p} \leq 0.05$.

As pain severity was low at baseline among all participants, with the mean and median values at 'mild' (ie, approximately 1 ), we dichotomised the original five-point severity scale into $0=$ no or mild pain and $1=$ uncomfortable, miserable or intense pain. Dichotomised low-exposure/high-exposure scores were also created, comparing below versus above median values of the current sample for RULA elements and HAL scores.

Generalised estimating equation Poisson models ${ }^{25}$ were then used to examine how large the prevalence of pain or exposure was in the intervention group relative to the control group as a function of the intervention (no/yes). The effect of the intervention was expressed as the prevalence ratio (PR) and its corresponding 95\% CI. All statistical analyses were performed using Stata V.11.

\section{RESULTS}

\section{Study schedule and flow diagram}

The study was conducted when the legislature was not in session. Figure 2 presents the study schedule and flow diagram. Each study phase (\#) took approximately 1 month to complete, sequentially: (1) baseline evaluations, (2) implementation and training of the intervention for the intervention group, (3) follow-up training for the intervention group and training on keyboard shortcuts to both groups. (4) Postintervention evaluations were conducted 3 months after the follow-up trainings (month 7). (5) Exit telephone interviews about perceived physical work demands over the study were conducted with all participants 1 month after the study ended.

We attempted to collect baseline and postintervention interviewer-administered data on the same day of each participant's observational exposure assessment, if she/he was available.

\section{Participant flow}

There were 418 agency employees, of whom 152 volunteered to participate. Among these, 39 were ineligible: 36 of these volunteers were asymptomatic, two had recently suffered acute traumas from motor vehicle accidents, and one was leaving the agency in 5 months. Thus, 113 volunteers were eligible, resulting in a participation rate of $27 \%(113 / 418) ; 56$ and 57 participants were assigned to the intervention and control groups, respectively. All participants from the intervention group completed the study, while four participants from the control group were lost to follow-up, resulting in 109 participants for analysis. One of these four participants was unavailable postintervention due to a change in legislators, another became a legislator, and two declined to continue citing lack of time (figure 2).

\section{Baseline determinants}

Fifty-three determinants were collected. No differences in distributions were found between intervention and control groups for any determinants (tables 1 and 2).

\section{Without and with an intention-to-treat approach}

Study results were compared between intervention and controls groups after excluding the four lost to follow-up $(n=109)$ and, as an intention-to-treat approach, after including the lost to follow-up $(n=113)$. All outcome values from the control group were imputed from baseline values. When comparing results without and with an intention-to-treat approach $(\mathrm{n}=109$ and $n=113$, respectively), no substantial findings were observed for any outcomes. To simplify analyses and limit assumptions, we chose not to use an intention-to-treat approach.

\section{Pain severity and PR}

Regional mean pain severity was low within the cohort at baseline $(=0.8$ for both intervention and control groups, scale range $0-4)$ and distributions between groups were similar (table 3). Since pain may have been associated with increased physical work over the study, we examined self-reported physical work demands, postintervention and found they were stable between groups. Mean decreases in pain severity were seen for intervention and control groups in proximal UEs, postintervention (table 3 ).

There were no significant differences in PRs for pain between groups in any anatomical regions. Although not reaching statistical significance, a protective effect in pain was seen on the dominant side of the intervention group, while an increase in pain was found on their distal non-dominant side (table 4).

\section{Exposure intensity and PRs}

Magnitude of posture (range of motion) and frequency (repetition) of hand activity for all RULA elements and HAL scores were similar between groups at baseline (table 3). With the exception of the spine/lower extremities, the intervention group showed mean decreases in non-neutral postures in RULA elements, postintervention. The opposite effects were seen in the 


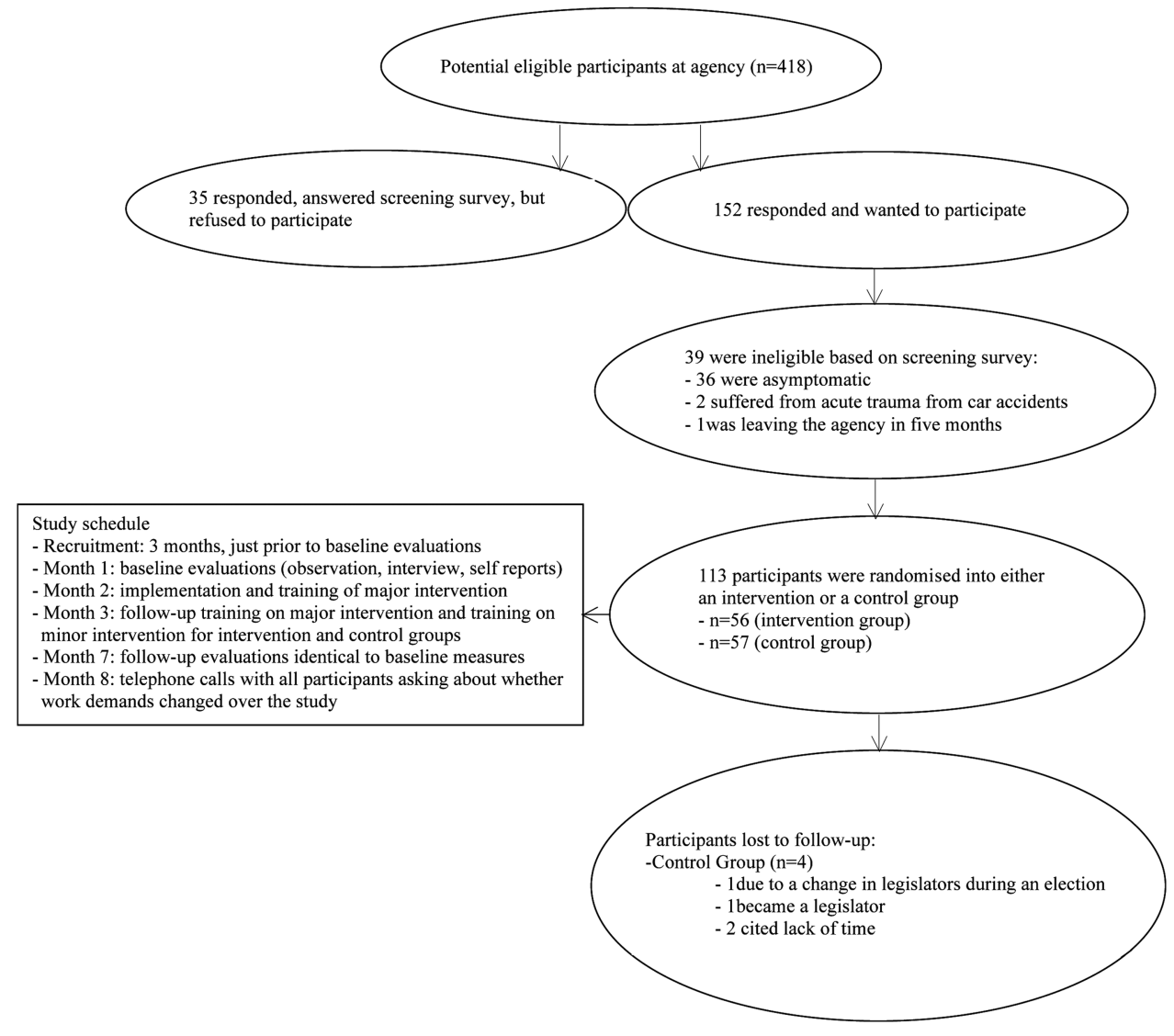

Figure 2 Flow diagram and study schedule of participants.

control group: increases in non-neutral postures were seen in all RULA elements except for the spine/lower extremities. An increase in mean hand activity in the non-dominant side was observed in the intervention group (significant), while distributions for all other paired pre-post tests in hand activity were similar between groups (table 3).

PRs showed decreases in two of five RULA elements in the intervention group postintervention, both on which were located on the non-dominant side (table 4). While trends in decreased exposure were seen in the other RULA elements of the intervention group, findings approximated but did not reach statistically significance. There was an increase in hand activity on the non-dominant side of the intervention group, postintervention (significant). No other significant findings in hand activity were observed between groups, postintervention (table 4).

\section{Secondary outcome variables}

Two dependent variables differed between groups postintervention: use of UE support (intervention group, $\mathrm{n}=22,39 \%$, control group, $\mathrm{n}=37,70 \%, \mathrm{p}<0.01$ ) and ergonomic knowledge. For this latter variable, the intervention had a significant effect on what is an 'ergonomically correct workspace' (intervention group, $\mathrm{n}=55,98 \%$, control group, $\mathrm{n}=0,0 \%, \mathrm{p}<0.001$ ).

\section{Self-reported effects of major intervention}

Postintervention evaluations asked the intervention group to rate certain effects of the engineering controls. Most participants $(73 \%)$ reported the KBT reduced pain, while $7 \%$ reported it increased pain. A lower percentage $(43 \%)$ of participants reported the TP reduced pain, while a similar percentage (9\%) reported it increased pain. Findings regarding equipment preference were consistent with pain reduction: $87 \%$ preferred using the KBT, while $50 \%$ of participants preferred using the TP. The majority of participants $(91 \%)$ had no difficulty using the KBT, while $50 \%$ had no difficulty using the TP. Almost one-half $(46 \%)$ thought that the KBT improved productivity, but only $13 \%$ reported the TP improved productivity.

\section{DISCUSSION}

The effect of the intervention, measured by PRs (table 4), showed no statistically significant differences in pain between groups in any anatomical region. Two of five RULA elements showed decreases in non-neutral postures in the intervention group, both of which were located on the non-dominant side. The intervention increased hand activity on the non-dominant side.

The findings are consistent with the Armstrong et $a l^{10}$ exposure-response model. Approximating but not reaching statistical significance, a protective effect in pain in the dominant UE may have occurred because of lower exposure in this extremity, postintervention. These results may also reflect the small sample size or a low sensitivity of study scales.

Pain and exposure can be measured using three different dimensions: severity/magnitude, frequency and duration. In the control group, proximal UE mean pain severity was reduced, but the magnitude of non-neutral posture was increased in the majority of RULA elements (table 3). Static UE loading, which represents the duration dimension of exposure, was also measured. The intervention group reported less UE support, postintervention. A review of RCTs and a prospective study ${ }^{26}$ reported UE forearm support may be associated with decreased proximal loading and pain. The control group used the desktop for UE forearm support, while the intervention group did not. 
Table 1 Descriptive statistics for categorical variables at baseline for intervention and control groups

\begin{tabular}{|c|c|c|c|c|c|}
\hline \multirow[b]{2}{*}{ Variable } & \multicolumn{2}{|c|}{ Intervention $(n=56)$} & \multicolumn{2}{|c|}{ Control $(n=53)$} & \multirow[b]{2}{*}{ p Value } \\
\hline & $\mathrm{n}$ & Per cent & $\mathrm{n}$ & Per cent & \\
\hline \multicolumn{6}{|l|}{ Individual risk factors } \\
\hline Female & 22 & 39.3 & 15 & 28.3 & 0.30 \\
\hline Education ( $<2$ years college) & 7 & 12.5 & 11 & 20.8 & 0.31 \\
\hline Race (white) & 50 & 89.3 & 44 & 83.0 & 0.41 \\
\hline Marital status (married) & 41 & 73.2 & 37 & 69.8 & 0.83 \\
\hline \multicolumn{6}{|l|}{ Salary } \\
\hline$\leq \$ 35000$ & 2 & 3.6 & 4 & 7.5 & \\
\hline$>\$ 35000-75000$ & 28 & 50.0 & 29 & 54.8 & \\
\hline$>\$ 75000$ & 26 & 46.4 & 20 & 37.7 & 0.49 \\
\hline \multicolumn{6}{|l|}{ House work (h/week) } \\
\hline$<3$ & 13 & 23.2 & 9 & 17.0 & \\
\hline $3-6$ & 19 & 33.9 & 21 & 39.6 & \\
\hline$>6$ & 24 & 42.9 & 23 & 43.4 & 0.68 \\
\hline Child or elder care (yes) & 25 & 44.6 & 27 & 50.9 & 0.57 \\
\hline Smoking status (yes) & 3 & 5.4 & 6 & 11.3 & 0.36 \\
\hline Handedness (left) & 7 & 12.5 & 8 & 15.1 & 0.78 \\
\hline Traditional mousing hand (left) & 1 & 1.8 & 3 & 5.7 & 0.35 \\
\hline Current systemic or metabolic morbidity & 8 & 14.3 & 3 & 5.7 & 0.20 \\
\hline \multicolumn{6}{|l|}{ Body mass index $\left(\mathrm{kg} / \mathrm{m}^{2}\right)$} \\
\hline Males $\leq 26=$ no & 41 & 73.2 & 39 & 73.6 & 0.97 \\
\hline Females $\leq 24=$ no & 48 & 85.7 & 44 & 83.0 & 0.70 \\
\hline Sick leave in past 8 weeks due to a musculoskeletal problem & 5 & 8.9 & 5 & 9.4 & 1.00 \\
\hline \multicolumn{6}{|l|}{ Length of musculoskeletal pain (years) } \\
\hline$<1$ & 6 & 10.7 & 6 & 11.3 & \\
\hline 1 & 7 & 12.5 & 5 & 9.4 & \\
\hline 2 & 7 & 12.5 & 6 & 11.3 & \\
\hline$>3$ & 36 & 64.3 & 36 & 68.0 & 0.97 \\
\hline Exacerbation of pain in past 4 weeks (yes) & 4 & 7.1 & 1 & 1.9 & 0.36 \\
\hline Current herniated disc low back or neck (yes) & 4 & 7.1 & 4 & 7.5 & 1.00 \\
\hline Seeking medical care in past 4 weeks (yes) & 9 & 16.1 & 9 & 17.0 & 1.00 \\
\hline Active workers' compensation claim (yes) & 0 & 0.0 & 1 & 1.9 & 0.49 \\
\hline Currently taking any medication (yes) & 8 & 14.3 & 4 & 7.5 & 0.36 \\
\hline Orthopedic surgery in past 5 years (yes) & 6 & 10.7 & 1 & 1.9 & 0.11 \\
\hline \multicolumn{6}{|l|}{ Modified work ability index (WAI)* } \\
\hline Unlikely or not certain & 7 & 12.5 & 3 & 5.7 & \\
\hline Relatively certain & 49 & 87.5 & 50 & 94.3 & 0.32 \\
\hline \multicolumn{6}{|l|}{ Daily physical activity $>3$ time per week for $>30 \mathrm{~min}$} \\
\hline Yes & 33 & 58.9 & 23 & 43.4 & 0.13 \\
\hline \multicolumn{6}{|l|}{ Trouble sleeping } \\
\hline No & 53 & 94.6 & 51 & 96.2 & \\
\hline Yes & 3 & 5.4 & 2 & 3.8 & 1.00 \\
\hline \multicolumn{6}{|l|}{ Department/job title } \\
\hline \multicolumn{6}{|l|}{ Department } \\
\hline Caucus (political party affiliation) & 30 & 56.6 & 33 & 58.9 & \\
\hline Technical branch & 13 & 24.5 & 10 & 17.9 & \\
\hline Management & 13 & 24.5 & 10 & 17.9 & 0.70 \\
\hline \multicolumn{6}{|l|}{ Job title } \\
\hline Assistant & 21 & 37.5 & 23 & 43.4 & \\
\hline Director & 14 & 25.0 & 12 & 22.6 & \\
\hline Analyst & 6 & 10.7 & 7 & 13.2 & \\
\hline Other & 15 & 26.8 & 11 & 20.8 & 0.84 \\
\hline \multicolumn{6}{|l|}{ Mechanical/temporal loads } \\
\hline Upper extremity (UE) support (yes) & 41 & 73.2 & 35 & 66.0 & 0.89 \\
\hline Wrist bend or twist (yes) & 42 & 75.0 & 42 & 79.2 & 0.70 \\
\hline High finger effort (yes) & 40 & 71.4 & 41 & 77.4 & 0.90 \\
\hline Hold neck and UE in static posture (yes) & 50 & 89.3 & 48 & 90.6 & 0.80 \\
\hline Deadline (yes) & 50 & 89.3 & 51 & 96.2 & 0.14 \\
\hline
\end{tabular}


Table 1 Continued

\begin{tabular}{|c|c|c|c|c|c|}
\hline \multirow[b]{2}{*}{ Variable } & \multicolumn{2}{|c|}{ Intervention $(\mathrm{n}=56)$} & \multicolumn{2}{|c|}{ Control $(n=53)$} & \multirow[b]{2}{*}{ p Value } \\
\hline & $\mathbf{n}$ & Per cent & $\mathbf{n}$ & Per cent & \\
\hline Overtime (yes) & 32 & 57.1 & 25 & 47.2 & 0.51 \\
\hline Hold object by pinching (yes) & 35 & 62.5 & 28 & 52.8 & 0.13 \\
\hline \multicolumn{6}{|l|}{ Daily break time (min) } \\
\hline 30 & 28 & 50.0 & 21 & 39.6 & \\
\hline 60 & 22 & 39.3 & 27 & 51.0 & \\
\hline 90 & 6 & 10.7 & 5 & 9.4 & 0.58 \\
\hline Other than computer, repetitive work (yes) & 18 & 32.1 & 20 & 37.7 & 0.60 \\
\hline Work multiple jobs using computer (yes) & 10 & 17.9 & 8 & 15.1 & 0.80 \\
\hline \multicolumn{6}{|l|}{ Weekly time spent on home computer use (h) } \\
\hline $0-3$ & 23 & 41.0 & 26 & 49.0 & \\
\hline $3-6$ & 10 & 17.9 & 9 & 17.0 & \\
\hline$>6$ & 23 & 41.1 & 18 & 34.0 & 0.69 \\
\hline \multicolumn{6}{|c|}{ Weekly time spent on personal digital assistant or cell phone (h) } \\
\hline $0-3$ & 37 & 66.1 & 39 & 73.6 & \\
\hline $3-6$ & 8 & 14.3 & 3 & 5.7 & \\
\hline$>6$ & 11 & 19.6 & 11 & 20.7 & 0.69 \\
\hline \multicolumn{6}{|l|}{ Ergonomic knowledge (none or little) } \\
\hline Overall ergonomic knowledge & 46 & 82.1 & 45 & 84.9 & 0.70 \\
\hline Risk factors & 50 & 89.3 & 46 & 86.8 & 0.69 \\
\hline Ergonomically correct posture & 48 & 85.7 & 44 & 83.0 & 0.70 \\
\hline Ergonomically correct workspace & 51 & 91.2 & 45 & 84.9 & 0.32 \\
\hline \multicolumn{6}{|l|}{ Psychosocial exposures } \\
\hline Supervisor support (low)† & 40 & 71.4 & 43 & 81.1 & 0.88 \\
\hline \multicolumn{6}{|l|}{ Job satisfaction } \\
\hline Somewhat or very satisfied (yes) & 46 & 82.7 & 46 & 86.8 & 0.84 \\
\hline
\end{tabular}

Static proximal loading in the intervention group may have been driving these particular results.

Higher pain prevalence in the distal non-dominant UE of the intervention group was unanticipated, postintervention. The use of a low, negatively tilted $\mathrm{KBT}^{12} 27$ and two pointing devices was expected to redistribute an individual's exposure profile and consequently reduce overall pain.

Dominant and non-dominant UE non-neutral postures were hypothesised to improve with the use of bilateral, simultaneously used pointing devices. A laboratory study that examined non-dominant (left) versus dominant mouse use found nondominant mousing reduced postural exposures on that side, but comparable results were not observed on the dominant side; however, that study did not use devices simultaneously in both hands. ${ }^{28}$ Similar to the above study, significant improvements in this study were only found in non-dominant postures (table 4).

Hand activity associated with mouse use in dominant and nondominant hands was predicted to be more equally distributed with two pointing devices. The secondary pointing device was only designed to supplement, not supplant, the primary pointing device.

Table 2 Descriptive statistics for continuous variables at baseline for intervention and control groups

\begin{tabular}{|c|c|c|c|c|c|}
\hline \multirow[b]{2}{*}{ Variable } & \multicolumn{2}{|c|}{ Intervention $(n=56)$} & \multicolumn{2}{|c|}{ Control $(n=53)$} & \multirow[b]{2}{*}{ p Value } \\
\hline & Mean & $95 \% \mathrm{Cl}$ & Mean & $95 \% \mathrm{Cl}$ & \\
\hline \multicolumn{6}{|l|}{ Individual risk factors } \\
\hline Age & 43 & 40.0 to 47.0 & 44 & 40.0 to 47.0 & 0.92 \\
\hline \multicolumn{6}{|l|}{ Mechanical/temporal loads } \\
\hline Hours/week on keyboard & 21 & 18.0 to 23.0 & 23 & 21.0 to 26.0 & 0.19 \\
\hline Hours/week on mouse & 22 & 20.0 to 25.0 & 25 & 23.0 to 28.0 & 0.19 \\
\hline Hours on computer without break & 2.3 & 2.0 to 2.5 & 2.0 & 1.8 to 2.2 & 0.14 \\
\hline Years worked in job title & 6.2 & 4.4 to 8.0 & 7.5 & 5.6 to 9.4 & 0.32 \\
\hline Years worked at agency & 9.8 & 7.7 to 11.9 & 10.4 & 8.1 to 12.7 & 0.70 \\
\hline Daily hours telephone use & 1.9 & 1.5 to 2.3 & 1.8 & 1.6 to 2.1 & 0.87 \\
\hline Years of computer use & 21.8 & 20.1 to 23.4 & 20.6 & 19.0 to 22.2 & 0.31 \\
\hline \multicolumn{6}{|l|}{ Psychosocial exposures } \\
\hline Linear job strain* & 67.5 & 65.6 to 69.4 & 68.4 & 66.7 to 70.1 & 0.48 \\
\hline
\end{tabular}


Table 3 Baseline and postintervention means of outcome variables by study group

\begin{tabular}{|c|c|c|c|c|}
\hline Outcome variable & $\begin{array}{l}\text { Intervention group } \\
\text { baseline means } \\
(n=56)(95 \% \mathrm{Cl})\end{array}$ & $\begin{array}{l}\text { Intervention group } \\
\text { postintervention } \\
\text { means }(n=56)(95 \% \mathrm{Cl})\end{array}$ & $\begin{array}{l}\text { Control group } \\
\text { baseline means } \\
(n=53)(95 \% \mathrm{Cl})\end{array}$ & $\begin{array}{l}\text { Control group } \\
\text { postintervention means } \\
(n=53)(95 \% \mathrm{Cl})\end{array}$ \\
\hline \multicolumn{5}{|l|}{ Regional pain severity } \\
\hline Dominant proximal UE & $1.3(1.0$ to 1.6$)$ & $0.7(0.4 \text { to } 1.0)^{*}$ & 1.5 (1.2 to 1.8$)$ & $1.0(0.7 \text { to } 1.3)^{*}$ \\
\hline Non-dominant proximal UE & 1.4 (1.1 to 1.7$)$ & $0.8(0.5 \text { to } 1.2)^{*}$ & $1.2(0.9$ to 1.4$)$ & $0.8(0.5 \text { to } 1.1)^{*}$ \\
\hline Dominant distal UE & $0.5(0.2$ to 0.8$)$ & $0.2(-0.1$ to 0.5$)$ & $0.4(0.2$ to 0.6$)$ & $0.3(0.0$ to 0.6$)$ \\
\hline Non-dominant distal UE & $0.3(0.1$ to 0.4$)$ & $0.2(-0.1$ to 0.5$)$ & $0.3(0.0$ to 0.5$)$ & $0.2(0.0$ to 0.4$)$ \\
\hline \multicolumn{5}{|c|}{ RULA non-neutral posture magnitude } \\
\hline Dominant UE & 19.5 (18.2 to 20.9$)$ & $15.2(14.0 \text { to } 16.7)^{*}$ & 18.8 (17.3 to 20.4$)$ & $21.7(20.4 \text { to } 22.5)^{*}$ \\
\hline Non-dominant UE & $16.3(15.1$ to 17.5$)$ & $11.9(10.7 \text { to } 13.1)^{*}$ & $16.2(14.8$ to 17.7$)$ & $19.5(16.9 \text { to } 22.0)^{*}$ \\
\hline Spine and lower extremities & 9.7 (8.8 to 10.6) & 9.6 (8.8 to 10.3$)$ & 9.2 (8.2 to 10.2 ) & $9.2(8.0$ to 10.1$)$ \\
\hline Full dominant RULA & $29.2(27.4$ to 31.1$)$ & $26.5(25.2 \text { to } 27.9)^{*}$ & 28.0 (25.8 to 30.2$)$ & $30.3(28.1 \text { to } 32.2)^{*}$ \\
\hline Full non-dominant RULA & $26.0(24.2$ to 27.8$)$ & $23.1(23.4 \text { to } 24.9)^{*}$ & 25.4 (23.1 to 27.7$)$ & $28.1(25.8 \text { to } 30.2)^{*}$ \\
\hline \multicolumn{5}{|l|}{ Hand activity level (HAL) repetition } \\
\hline Dominant UE & 4.1 (3.7 to 4.6$)$ & 3.7 (3.2 to 4.1$)$ & 4.1 (3.6 to 4.5$)$ & 4.5 (4.1 to 4.9$)$ \\
\hline Non-dominant UE & $2.4(1.9$ to 2.9$)$ & $3.9(3.3 \text { to } 4.4)^{*}$ & 2.1 (1.7 to 2.5$)$ & $2.0(1.6$ to 2.3$)$ \\
\hline
\end{tabular}

The increase in hand activity in the intervention group may have occurred from the 11 functions of the TP. While this may have provided the intervention group with more opportunities to efficiently (and quickly) complete activities than their traditional three-function mouse, the increased functionality may have led to greater pain. A randomised intervention study that provided track balls in the dominant (right) UE found they increased incident musculoskeletal disorders on the right but decreased prevalent pain on that side. ${ }^{6}$ These findings may suggest the mechanisms for onset of and recovery from pain are different, ${ }^{29} 30$ which might highlight the importance of examining primary and secondary prevention.

Four other possible explanations for results are listed below. Postintervention follow-up time was limited to 3 months because we were unable to gain access after the legislative

Table 4 Effect of the intervention between the intervention and control group, measured by prevalence ratio ( $P R ; n=109)$

\begin{tabular}{|c|c|}
\hline Outcome variable & $\operatorname{PR}(95 \% \mathrm{Cl}) * \dagger$ \\
\hline \multicolumn{2}{|l|}{ Regional pain } \\
\hline Dominant proximal UE & $0.9(0.7$ to 1.2$)$ \\
\hline Non-dominant proximal UE & $1.0(0.8$ to 1.4$)$ \\
\hline Dominant distal UE & $0.8(0.5$ to 1.3$)$ \\
\hline Non-dominant distal UE & $1.2(0.6$ to 2.2$)$ \\
\hline \multicolumn{2}{|l|}{ RULA non-neutral posture } \\
\hline Dominant UE & $0.9(0.9$ to 1.0$)$ \\
\hline Non-dominant UE & 0.9 (0.8 to 0.9$)$ \\
\hline Spine and lower extremities & $0.8(0.5$ to 1.2$)$ \\
\hline Full dominant RULA & $0.9(0.9$ to 1.0$)$ \\
\hline Full non-dominant RULA & $0.8(0.8$ to 0.9$)$ \\
\hline \multicolumn{2}{|l|}{ Hand activity level (HAL) score } \\
\hline Dominant UE & $0.9(0.8$ to 1.0$)$ \\
\hline Non-dominant UE & $1.4(1.2$ to 1.6$)$ \\
\hline
\end{tabular}

session began. However, it is suggested that at least a 1 year follow-up is desirable. ${ }^{31}$ A traditional wrist rest was integrated into the KBT. However, wrist rests have been associated with increased UE pain, perhaps due to mechanical compression in distal regions. ${ }^{26}$ The intervention did not include forearm supports; these have been shown to reduce muscle loading in the UEs of computer workers, and higher muscle loads have been associated with UE pain. ${ }^{32}$ Baseline mean pain severity levels were low within the cohort. We may have experienced floor effects, reducing room for pain reduction.

While the study had several strengths, results should be viewed with respect to its limitations. Strengths included its randomised design ${ }^{33}$ and the measurement of a wide range of potential confounders. We conducted observational exposure assessments rather than relying on self-reports and only used one ergonomist to conduct observational assessments and exposure and health interviews for better reproducibility. The control group had less self-reported overall ergonomic knowledge than the intervention group, postintervention (intervention group $=57.1 \%$, control group $=37.7 \%, p=0.04$ ), which may indicate contamination was minimal. The intervention involved engineering controls, which would have made contamination less likely. Specifically, the control group was issued standard agency equipment. Without engineering controls, a reduction in non-neutral postures and hand activity in the dominant hand may be difficult to achieve.

Limitations include lack of blinding following knowledge of intervention status, which may have led to measurement error. This would most likely have resulted in differential misclassification of outcomes with respect to 'exposure.' The participation rate was low $(113 / 418=27 \%)$. However, it has been suggested that low participation rates are not likely to have a substantial influence on intervention-disease associations or point estimates. ${ }^{34}$ Residual confounding may have occurred despite randomisation, but we collected and examined 53 potential confounders. There may have been inadequate concealment of random allocation, although the randomisation sequence was generated by an epidemiologist blind to study objectives and allocation was hidden until after baseline measures were conducted and just prior to intervention implementation. There 
may be differential attrition between the intervention and control group; however, the numbers lost to follow-up in the control group were small $(n=4)$ and participants' reasons appeared unrelated to the intervention. Despite using engineering controls, contamination might have occurred, since intervention and control group participants' workstations were often adjacent to each other and personal contact was frequent.

Despite the limitations, we believe the use of two pointing devices in right and left hands may still have a role in secondary prevention. Mechanical exposures following a physical intervention would more likely be reduced before a decrease in pain, as the musculoskeletal system requires substantial periods for repair and remodelling.

Recommendations for future studies include use a longer postintervention period before reassessment of measurements. Higher baseline pain severities in the cohort may have resulted in pain reductions in the intervention group, as possible floor effects might have limited the intervention's impact. Since increased TP use in the non-dominant hand may have increased pain on this side, another recommendation is to limit their number of programmable functions to three.

The study provided a clinical perspective on symptomatic participants working with low pain levels, such as the number of lost workdays experienced and whether medication was taken to manage symptoms and, for pain severity, on the effectiveness of engineering controls. The magnitude of posture and frequency of hand activity have implications for ergonomic design. The PRs may help identify effective (or ineffective) interventions for setting public health policies involving computer work.

\section{CONCLUSION}

No significant differences in pain between groups were found in any anatomical regions, postintervention. Decreases in nonneutral postures were observed in two of five RULA elements in the intervention group and an increase in hand activity was seen in their non-dominant hand. To reduce hand activity in the nondominant UE, a KBT and TP used in the non-dominant hand may not be the best engineering controls to use.

Acknowledgements The authors thank the Cirque Corporation for donating the Smart Cat touch pads, and K/V Waterloo, Grand Stands and Ergo Express for their assistance in this study. The authors also thank the Office of Legislative Management and the study participants who work in this state government.

Contributors All authors listed in the title made significant contributions to the study concept and design, acquisition of data, or analysis and interpretation of data; drafting/revising the manuscript for important intellectual content; and have approved the final version to be published.

Funding This work was supported, in part, by a Centers for Disease Control and Prevention, National Institute for Occupational Safety and Health New York/New Jersey Education and Research Center Pilot Project Grant (5T42OH008422) and by a Promotional of Doctoral Studies scholarship (PODS) from the Foundation for Physical Therapy.

\section{Competing interests None.}

Ethics approval IRB at the Mount Sinai School of Medicine, IRB at the University of Massachusetts Lowell, a Certificate of Confidentiality from the CDC, NIOSH.

Provenance and peer review Not commissioned; externally peer reviewed.

\section{REFERENCES}

Wahlström J. Ergonomics, musculoskeletal disorders and computer work. Occup Med (Lond) 2005;55:168-76.

2 United States Bureau of Labor Statistics. Nonfatal occupational injuries and illnesses requiring days away from work, 2011. Washington, DC: BLS, Department of Labor, 2012.

3 Hoe V, Urquhart DM, Kelsall HL, et al. Ergonomic design and training for preventing work-related musculoskeletal disorders of the upper limb and neck in adults. Cochrane Database Syst Rev 2012;8:1-112.
4 Brewer S, Van Eerd D, Amick BC, et al. Workplace interventions to prevent musculoskeletal and visual symptoms and disorders among computer users: a systematic review. J Occup Rehabil 2006;16:317-50.

5 Leyshon R, Chalova K, Gerson L, et al. Ergonomic interventions for office workers with musculoskeletal disorders: a systematic review. Work 2010;35:335-48.

6 Rempel D, Krause N, Goldberg R, et al. A randomised controlled trial evaluating the effects of two workstation interventions on upper body pain and incident musculoskeletal disorders among computer operators. Occup Env Med 2006:63:300-6.

7 Feuerstein M, Harrington CB. Secondary prevention of work-related upper extremity disorders: recommendations from the Annapolis conference. J Occup Rehabil 2006:16:393-9.

8 Schultz IZ, Stowell AW, Feuerstein M, et al. Models of return to work for musculoskeletal disorders. J Occup Rehabil 2007;17:327-52.

9 Dew K, Keefe V, Small K. 'Choosing'to work when sick: workplace presenteeism. Social Sci Med 2005;60:2273-82.

10 Armstrong TJ, Buckle P, Fine LJ, et al. A conceptual model for work-related neck and upper-limb musculoskeletal disorders. Scand J Work Env Health 1993; 19:73-84

11 Lassen CF, Mikkelsen S, Kryger Al, et al. Elbow and wrist/hand symptoms among 6,943 computer operators: a 1-year follow-up study (the NUDATA study). Am J Ind Med 2004;46:521-33.

12 Hedge A, Powers JR. Wrist postures while keyboarding: effects of a negative slope keyboard system and full motion forearm supports. Ergonomics 1995:38:508-17.

13 Rempel D, Bach JM, Gordon L, et al. Effects of forearm pronation/supination on carpal tunnel pressure. J Hand Surg Am 1998;23:38-42.

14 Wong D, Hocenberry-Eaton M, Wilson A, et al. Wong's essentials of pediatric nursing. St. Louis: Mosby, Inc., 2001:1301.

15 Hales T, Sauter S, Petersen M, et al. Health Hazard Evaluation Report: US West Communications. HETA 89-299-2230, Phoenix, Minneapolis, Denver: US Department of Health and Human Services, Public Health Service, CDC, NIOSH, 1992.

16 IImarinen J. The Work Ability Index (WAI). Occup Med 2007;57:160.

17 McAtamney L, Corlett NE. RULA: a survey method for the investigation of work-related upper limb disorders. Appl Ergon 1993;24:91-9.

18 Lueder R. A proposed RULA for computer users. Proceedings of the Ergonomics Summer Workshop, University of California Berkeley, Center for Occupational and Environmental Health, San Francisco: Continuing Educaiton Program, 1996.

19 Latko WA, Armstrong TJ, Foulke JA, et al. Development and evaluation of an observational method for assessing repetition in hand tasks. Am Ind Hyg Assoc J 1997;58:278-85

20 Landsbergis PA, Schnall PL, Warren K, et al. Association between ambulatory blood pressure and alternative formulations of job strain. Scand J Work Environ Health 1994:349-63.

21 Karasek R, Brisson C, Kawakami N, et al. The Job Content Questionnaire (JCQ): an instrument for internationally comparative assessments of psychosocial job characteristics. J Occup Health Psychol 1998:3:322-55.

22 Judge TA, Thoresen CJ, Bono JE, et al. The job satisfaction-job performance relationship: a qualitative and quantitative review. Psychol Bull 2001;127:376-407.

23 Robertson MM, O'Neill MJ. Reducing musculoskeletal discomfort: effects of an office ergonomics workplace and training intervention. Int J Occup Saf Ergon 2003:9:491-502

24 Bernaards CM, Ariëns GA, Knol DL, et al. The effectiveness of a work style intervention and a lifestyle physical activity intervention on the recovery from neck and upper limb symptoms in computer workers. Pain 2007;132:142-53.

25 Zou G. A modified Poisson regression approach to prospective studies with binary data. Am J Epidemiol 2004;159:702-6.

26 Marcus M, Gerr F, Monteilh $C$, et al. A prospective study of computer users: II. Postural risk factors for musculoskeletal symptoms and disorders. Am J Ind Med 2002:41:236-49.

27 Sauter SL, Schleifer LM, Knutson SJ. Work posture, workstation design, and musculoskeletal discomfort in a VDT data entry task. Hum Factors 1991;33:151-67.

28 Delisle A, Imbeau D, Santos B, et al. Left-handed versus right-handed computer mouse use: effect on upper-extremity posture. App/ Ergon 2004;35:21-8.

29 Carroll L, Hogg-Johnson S, Côté $P$, et al. Course and prognostic factors for neck pain in workers. Eur Spine J 2008;17:93-100.

30 Borghouts JAJ, Koes BW, Bouter LM. The clinical course and prognostic factors of non-specific neck pain: a systematic review. Pain 1998;77:1-13.

31 Westgaard R, Winkel J. Ergonomic intervention research for improved musculoskeletal health: a critical review. Int J Ind Ergon 1997;20:463-500.

32 Ranney D, Wells R, Moore A. Upper limb musculoskeletal disorders in highly repetitive industries: precise anatomical physical findings. Ergonomics 1995:38:1408-23.

33 Winkel J, Mathiassen SE. Assessment of physical work load in epidemiologic studies: concepts, issues and operational considerations. Ergonomics 1994;37:979-88.

34 Galea S. Participation rates in epidemiologic studies. Ann Epidemiol 2007; 17:643-53. 